\title{
Predictors of finance management in dementia: managing bills and taxes matters
}

DOI:

$10.1017 / \mathrm{S} 1041610218000820$

\section{Document Version}

Accepted author manuscript

Link to publication record in Manchester Research Explorer

\section{Citation for published version (APA):}

Giebel, C. M., Flanagan, E., \& Sutcliffe, C. (2019). Predictors of finance management in dementia: managing bills and taxes matters. International Psychogeriatrics, 31(2), 277-286. https://doi.org/10.1017/S1041610218000820

\section{Published in:}

International Psychogeriatrics

\section{Citing this paper}

Please note that where the full-text provided on Manchester Research Explorer is the Author Accepted Manuscript or Proof version this may differ from the final Published version. If citing, it is advised that you check and use the publisher's definitive version.

\section{General rights}

Copyright and moral rights for the publications made accessible in the Research Explorer are retained by the authors and/or other copyright owners and it is a condition of accessing publications that users recognise and abide by the legal requirements associated with these rights.

\section{Takedown policy}

If you believe that this document breaches copyright please refer to the University of Manchester's Takedown Procedures [http://man.ac.uk/04Y6Bo] or contact uml.scholarlycommunications@manchester.ac.uk providing relevant details, so we can investigate your claim.

\section{OPEN ACCESS}




\title{
Predictors of finance management in dementia: Managing bills and taxes matters
}

\author{
Clarissa M Giebel ${ }^{1,2}$, Emma Flanagan ${ }^{3}$, Caroline Sutcliffe ${ }^{4}$ \\ ${ }^{1}$ Institute of Translational Medicine, University of Liverpool, Liverpool, UK \\ 2 CLAHRC NWC, University of Liverpool, Liverpool, UK \\ ${ }^{3}$ Norwich Medical School, University of East Anglia, Norwich, UK \\ ${ }^{4}$ Personal Social Services Research Unit, The University of Manchester, Manchester, UK
}

Correspondence should be addressed to: Clarissa Giebel, Waterhouse Building Block A, Institute of Translational Medicine, University of Liverpool, Liverpool, UK. Email: Clarissa.giebel@liverpool.ac.uk; Tel.: +44 (0) 1517955390 


\section{Abstract}

Objectives Finance management skills deteriorate early on in dementia, and can influence the ability to maintain control over personal affairs. The aim of this study was to assess the contributions of different types of cognition and motor functioning to finance management.

Design Cross-sectional analysis using secondary data

Setting Community living

Participants Baseline data from the Uniform Data Set from the National Alzheimer's Coordinating Centers were obtained and extracted up until December 2016.

Measurements Measures on everyday functioning (Functional Assessment Questionnaire) and cognition (memory, executive functioning, and language), the Clinical Dementia Rating Scale, and questions on Parkinsonian motor symptoms (gait disturbance, falls, tremors, slowness) were included. Data were analysed using bivariate correlation and linear regression analyses.

Results $A$ total of 9,383 cases were included in the analysis (Alzheimers Disease $(A D)=8,201$; behavioural variant fronto-temporal dementia (bvFTD) $=796$; Dementia with Lewy Bodies $(D L B)=386)$. Cognition and motor functioning varied significantly across $A D$, bvFTD, and DLB, with poorer motor functioning and poorer finance management skills in DLB than in AD and bvFTD. In the regression models, slowness, verbal fluency, executive functioning, and language, followed by age, gender, and diagnosis accounted for $13.8 \%$ of the variation in managing bills, and for $11.4 \%$ of the variation in managing taxes.

Conclusion Maintaining finance management abilities for as long as possible is important for people with dementia, to avoid potential financial exploitation. Findings from this study highlight avenues to pursue to delay deterioration in managing bills and taxes, and help maintain financial control.

Keywords: dementia; activities of daily living; finance management; cognition; motor disturbances 


\section{Introduction}

Neurodegenerative conditions such as dementia are characterised by deteriorating skills in performing basic and instrumental activities of daily living (bADLs/IADLs). These include using the telephone and shopping, whilst deficits with some activities may have a greater negative impact on the well-being of patients or carers than others (Beerens et al., 2016; Devanand et al., 2017; Giebel et al., 2017).

Finance management is one such IADL, and is frequently reported to be one of the first IADLs to deteriorate in dementia (Peres et al., 2008; Sudo \& Laks, 2017) and subject to impairment in mild cognitive impairment also (Berezuk et al., 2017). Financial abuse is unfortunately very common in older populations and in people with dementia, and has severe legal and financial ramifications (Manthorpe et al., 2012; Peisah et al., 2016). Managing finances is one of the few daily activities which has been broken down into subtasks. In particular, the Financial Capacity Instrument (Marson et al., 2000) first deconstructed finance management into six domains, including basic monetary skills; financial conceptual knowledge; cash transactions; chequebook management; bank statement management; and financial judgment. Griffith and colleagues (2003) added three further domains of bill payment; investment decision-making; and asset knowledge. Basic monetary skills and asset knowledge remain the best maintained finance domains in mild dementia (Griffith et al., 2003; Marson et al., 2000), with all other domains showing significant deteriorations early on. Findings from a recent systematic review by Sudo and Laks (2017) corroborates this, as more basic financial capacity skills were more preserved in the early stages of dementia, yet moderate stages were marked by impairments in all finance domains.

For IADLs in general, there are a variety of factors that can contribute to poor functioning, with some factors more pronounced in some subgroups than others. Depression, physical limitations and motor functioning, environmental limitations, cognitive deficits, as well as apathy have all been associated with poor IADL performance (Knapskog et al., 2014; Martyr et al., 2014; Woodbridge et al., 2016; Zawacki et al., 2002). Few studies have explored 
the predictors of individual activities however (Martyr et al., 2014; Moheb et al., 2017; Razani et al., 2011), and particularly the individual types of cognitive deficits that may predict poor performance on an individual task, including different forms of memory, executive function, and attention. Within the literature, poor finance management has been found to be associated particularly with executive functioning deficits (Moheb et al., 2017; Razani et al., 2007), highlighting the complex cognitive tasks involved when dealing with taxes, counting change, and paying bills, amongst others. Due to the established breakdown of finance management into subtasks, and increased levels of interest in understanding the predictors of individual IADLs, the next logical step is to explore whether and how different predictors contribute to the effective performance of individual subtasks. Considering the large number of different subtasks involved in finance management, it is possible that different factors, or the same factors but to different extents predict individual subtasks. By exploring these underpinning factors required for the successful performance of individual tasks, care management can translate these relationships into effective support strategies by focusing on the individual underlying predictors.

Motor function is another predictor of IADL functioning which varies across dementia subtypes. In Dementia with Lewy Bodies (DLB) for example, motor functioning is impaired to a greater extent than in Alzheimer's disease $(A D)$ as part of the disease profile (McKeith et al., 2006). Naturally, motor functioning is crucial for the efficacy and ease when performing everyday activities, such as driving or preparing a meal, although some tasks may be less influenced than others. Whilst the majority of evidence solely focuses on global IADL or ADL functioning (Cahn et al., 1998; de Paula et al., 2016; McKeith et al., 2006; Yoshii et al., 2016), little research has emerged to date which compared the contributions of both cognitive and motor functioning to IADL and ADL performance in dementia. Cahn and colleagues (1998) for example reported that executive functioning, but not simple motor function, predicted IADL performance in people with Parkinson's disease dementia. On the other hand, simple motor function, but not executive function, predicted overall ADL performance. With individual IADLs, 
and ADLs, deteriorating at different rates (Peres et al., 2008), it is important to understand the contributions of motor functioning to IADL independence for individual activities.

The objective of this study was to explore the predictors of finance management across different dementia subtypes in community-dwelling people with dementia with an informal caregiver. Whilst literature has highlighted the strong link between executive functioning and finance management, this study takes into consideration a range of potential predictors, including motor functioning, whilst also exploring two subtasks of finance management. Understanding the predictors of reduced finance management skills in dementia may help in translating this knowledge into practice.

\section{Method}

\section{Participants}

Data were obtained from the Uniform Data Set of the National Alzheimer's Coordinating Center (NACC), and were locked in December 2016 and extracted up to that date. Data were requested in August 2017 (ID request: 914). The Uniform Data Set collects routine data from 34 study centers across the USA. The entire data set included data from patients with either $A D$, behavioural-variant fronto-temporal dementia (bvFTD), DLB, corticobasal degeneration (CBD), or progressive supranuclear palsy (PSP) at baseline assessment only. The diagnoses were provided by clinicians at the 34 study centers. A diagnosis of $A D$ was based on recommendations from the National Institute on Aging - Alzheimer's Association workgroups (McKhann et al., 2011). A diagnosis of bvFTD was made based on the International Consensus Criteria for bvFTD (Raskovsky et al., 2011). A diagnosis of DLB, CBD, or PSP was based on established criteria (Armstrong et al., 2013; Bensimon et al., 2009; Ferman et al., 2006). For this study, only people with a diagnosis of dementia were included in the analysis (AD, bvFTD, DLB). 
Figure 1 shows the schematic overview of the data included in this study. Of the total 11,939 patients, 635 cases were excluded due to residency in a nursing home or other institutional setting. Of the 11,304 cases living in the community (in a single family residence; a retirement community; or in assisted living/ boarding home/ adult family home), 10,905 had an informal carer. Of those with informal carers, 10,806 had a CDR score between 0.5 and 3 , determining their level of severity of dementia, and were included. Those with a score of 0 were excluded. After these criteria were applied, 9,383 cases were included in the final analysis $(A D=8,201 ;$ bvFTD=796; $D L B=386)$. People with a diagnosis of PSP $(N=108), C B D$ $(\mathrm{N}=130)$, a mixed diagnosis $(\mathrm{N}=756)$, or a missing diagnosis (or diagnosis other than $A D$, bvFTD, DLB) were excluded from the analysis.

\section{[insert here Figure 1]}

\section{Measures}

The Functional Activities Questionnaire (FAQ) (Pfeffer et al., 1982) was used to measure the performance of 10 IADLs, including paying bills; managing taxes; shopping; hobbies; using kitchen appliances; meal preparation; remembering events; paying attention; remembering appointments; and travelling. The finance activity of paying bills also includes tasks of writing checks and balancing a checkbook, whilst managing taxes involves assembling tax records, business affairs, or papers. Each activity can be rated on a scale from '0' (no problems) to ' 3 ' (dependent).

The Neuropsychiatric Inventory Questionnaire (NPI-Q) (Kaufer et al., 2000) measured the presence and severity of 12 neuropsychiatric behaviours: delusions, hallucinations, agitation, depression, anxiety, elation, disinhibition, apathy, irritability, aberrant motor behaviour, sleep, and appetite change. Symptom severity is rated from ' 1 ' (mild) to '3' (severe).

Several neuropsychological tests were employed measuring global cognition with the Mini-Mental State Examination (MMSE; Folstein et al., 1975), working memory with digit forward and digit backward counts, executive functioning with the Trail Making Test $A$ and $B$ 
and the Wechsler Adult Intelligence Scale (WAIS; Wechsler et al., 1997), including verbal fluency (Animals, Vegetables), as well as language with the Boston Naming Test (Kaplan, 1983).

The Clinical Dementia Rating (CDR) scale (Morris, 1993) was employed to measure the severity of the dementia. The CDR Global score indicated the severity level, ranging from 0 (no dementia), 0.5 (questionable), 1 (mild), 2 (moderate), to 3 (severe).

Motor functioning was assessed by systematically collected data on the presence or absence of Parkinsonian motor symptoms of changes in gait disturbance, falls, tremors, and slowness.

\section{Data analysis}

Data were analysed using SPSS Version 23. Graphpad Prism 7 software was employed for creating diagrams. For the $F A Q_{\text {Total }}$ score, only those cases with complete data for all 10 activities were included. Where one or more values were missing or rated as non-applicable, these cases were excluded from the total score analysis.

Frequency analysis was employed to assess the demographic characteristics of each patient group and of the total sample. ANOVAs were performed to assess any variations amongst the groups for age, years of education, FAQ scores, CDR ratings, and for the performance on cognitive tests. Chi-square tests were conducted to assess any variations amongst groups for demographics of gender, ethnicity, marital status, carer relationship, and for the presence of Parkinsonian symptoms. Bivariate correlation analyses were employed separately to assess the correlation between demographic variables, cognitive, and motor symptoms with bills (1) and with taxes (2).

Multiple linear regression analysis was employed to explore the contributions of executive functioning, memory, and motor functioning on finance management. One regression model used paying bills and one managing taxes as the continuous outcome variable, respectively, whilst also controlling for age, gender, ethnicity, and education. A priori decisions were made to include additional variables, i.e. age and ethnicity, as well as diagnosis 
if found non-significant in the correlation analysis. This was because diagnosis was considered important because of the variations in cognition and motor symptomatology for each diagnosis. Because the independent variable 'diagnosis' was a non-binary categorical variable of three levels, diagnosis was recoded into two binary dummy variables: 'AD diagnosis' and 'bvFTD diagnosis'. Each diagnosis is mutually exclusive, so that scoring ' 0 ' on 'AD diagnosis' and ' 0 ' on 'bvFTD diagnosis' means a diagnosis of DLB. All variables reaching $p<.05$ level of significance were included in the model. All independent variables entered into the regression models were checked for multi-collinearity, and variables correlating above 0.70 were excluded.

\section{Results}

Demographic characteristics

Table 1 shows the demographic characteristics by dementia subtype. People with a diagnosis of bvFTD were significantly younger than those with AD or DLB, with a mean age of 63 years (+/-9). People with bvFTD or DLB were primarily male $(61.8 \%, 75.1 \%)$, whilst people with AD were primarily female (56.5\%). The majority of people with dementia were married, White Caucasian, and had an average of 14 to 15 years of education. Significantly fewer people with $A D$ were married than those with bvFTD and DLB; those from a Black or African ethnic background were most likely to present with AD; and people with AD had significantly fewer years of education. The large majority of people with dementia had a questionable or mild stage of dementia (77.2\%), according to the CDR, and fewer cases were in the advanced stages. Carers were predominantly female (66.3\%-83.7\%), White Caucasian, and spouses. There were significantly more adult child carers for people with $A D$ than for people with a diagnosis of bvFTD or DLB.

\section{[insert here Table 1]}


Cognitive and motor variations across dementia subgroups

Cognitive functioning was found to vary across dementia subtypes (Table 2). People with AD scored significantly lower on the MMSE than those with bvFTD or DLB, which was expressed in a difference of 2 points. People with DLB scored lower on digit span backward than people with $A D$, indicating poorer working memory. No variations were reported for digit span forward. For the executive functioning tests, people with bvFTD scored significantly lower than people with $A D$ and $D L B$ on Trail Making Test $A$ and $B$, whilst people with $A D$ performed lower than those with DLB also. On the WAIS and Boston Naming test, the same differences were observed, with people with bvFTD overall performing worse. For the fluency tests, people with bvFTD named on average fewer vegetables than those with $A D$, whilst no significant differences were observed for naming animals.

ANOVA with Bonferroni correction showed that people with DLB experienced significantly more symptoms of motor disturbance than those with $A D$ and bvFTD, whilst those with bvFTD experienced more gait problems, falls, tremors, and slowness compared to people with $\quad A D \quad\left[F_{\text {Gait }}(2,9323)=542.96, \quad p<.001 ; \quad F_{\text {Falls }}(2,9318)=173.23, \quad p<.001\right.$; $\left.F_{\text {Tremors }}(2,9339)=321.08 ; p<.001 ; F_{\text {Slowness }}(2,9346)=562.85, p<.001\right]$. Of the four symptoms, gait problems and slowness were the most evident across all three subtypes.

\section{[insert here Table 2]}

\section{Finance management abilities}

Paying Bills $\left(\right.$ Mean $\left._{\text {Total }}=2.21+/-1.03\right)$ and managing taxes $\left(\right.$ Mean $\left._{\text {Total }}=2.37+/-0.96\right)$ were the most impaired IADLs across the FAQ. In comparing the performance of those activities across the three dementia subtypes, ANOVA with Bonferroni posthoc correction revealed significantly poorer performance on bills for DLB and bvFTD patients compared to AD patients $[F(2,8203)=15.500, p<.001]$, and significantly poorer tax management abilities for DLB and bvFTD compared to AD cases $[F(2,7742)=13.377, \mathrm{p}<.001]$. Paying attention $(1.18+/-1.02)$ and using the stove $(1.02+/-1.19)$ were the best maintained skills. 
Figure 2 shows the degree of impairment for managing bills and taxes by dementia subtype and by dementia severity, ranging from a score of 0.5 on the CDR (indicating minimal severity) to a score of 3 (indicating severe). Findings show that the more severe the dementia, the more severe the deficits when trying to manage bills and taxes, with little variation across dementia subtypes with a score of 1,2 , or 3 . Only in the minimal severity stage, people with AD were significantly less impaired than people with bvFTD $(p<.05)$ and DLB $(p<.001)$ for bill management $[F(2,2451)=13.039, p<.001]$. For taxes, people with $A D$ were significantly less impaired than people with DLB $(p<.001)[F(2,2257)=8.485, p<.001]$.

\section{Correlates and predictors of finance management}

Those individual variables that were found to be associated significantly with bills and taxes for the entire sample in the bivariate correlation analysis were entered into the regression models. Dementia subtype was not found to be associated with performance on finance management tasks. Nevertheless, it was included in the regression model to establish whether it may still contribute to bills and taxes.

The multiple linear regression models are shown in Table 3. When using paying bills as the outcome variable, age, gender, executive function, language, verbal fluency, as well as falls and slowness explained $13.8 \%$ of the variation. The greatest predictors of paying bills were executive functioning (Standarised $B=-.255$ ) and verbal fluency (Standardised $B=-.140$ ), followed by a diagnosis of bvFTD (Standardised $B=.087$ ) and slowness (Standardised $B=.094$ ) Working memory approached significance but was not a predictor of this IADL.

In the model using tax management as the outcome variable, executive function, language, verbal fluency, as well as falls and slowness predicted $11.4 \%$ of the variation, in addition to age, gender, and dementia type. Executive functioning (Standardised $B=-.223$ ) and verbal fluency (Standardised $B=-.127$ ) were the biggest predictors of tax management abilities, followed by a diagnosis of bvFTD (Standardised B=.068) and slowness (Standardised $\mathrm{B}=.078)$. 


\section{[insert here Figure 2 and Table 3]}

\section{Discussion}

Problems with finance management can severely impair an individual's ability to maintain control of their life, and require them to rely on family members or others to support them. This study adds further insight into the individual contributors to this IADL in dementia. Importantly, with finance management being frequently broken down into separate tasks, this is one of the first studies that has explored the contributors to separate tasks of bills and taxes, showing that both cognitive and motor functions underpin the performance of finance management subtasks.

Cognition and motor functioning taken together predicted between $11 \%$ and $14 \%$ of the total variance in bill management and tax management. In particular, this study showed that executive function and letter fluency were the largest cognitive predictors for both bill management and tax management. Letter fluency is made up of verbal ability and the executive control of vocabulary, thereby linking in with executive function (Shao et al., 2014). When assessing the cognitive and psychological predictors of individual FAQ items, Martyr and colleagues (2014) showed that premorbid IQ predicted tax management in 100 people with dementia, and letter fluency and immediate memory, predicted bill management, with the latter supporting the present findings of bill management. One recent study further reported how executive functioning predicted impairments in finance management across different FTD subtypes (Moheb et al., 2017). Therefore, this study advances previous findings on finance management specific subtasks by widening the inquiry to predictors other than cognition.

In contrast to previous limited research, factors examined in the present study only predicted up to $14 \%$ of finance management skills, indicating some possible limitations in the analysis. Sherod and colleagues (2009) for example found that written arithmetic skills predicted $55 \%$ of overall finance management skills in mild $A D$, a variable not available from the NACC data set. Furthermore, in this study finance management was broken down into individual subtasks, each of which may contain different sets of cognitive predictors. However, 
Martyr and colleagues (2014) reported $21 \%$ of bill management and $8 \%$ of tax management to be predicted by different types of cognition, including memory, verbal executive functioning, and language. The higher variance for bill management may be explained by the presence of anxiety and depression measures in the regression models, with mood a significant predictor alongside letter fluency and immediate memory. Therefore, the present findings support limited previous research on finance subtasks in the area of cognition, whilst motor functioning provides further novel insights into the predictors of finance management.

Motor functioning is an important additional predictor of finance management. Due to the disease symptomatology, this symptom is specifically pronounced in the DLB cases. Whilst all four types of motor dysfunction were correlated with bill and tax management, slowness and falls were found to predict impairment with both tasks. It is also worth noting that slowness was the most prominent motor disturbance across all three dementia subtypes, which may explain the fact that slowness was the strongest motor predictor of those reported. In particular, slowness was more predictive of tax management skills than bill management, indicating that not only different sets of motor symptoms predict finance subtasks, something which has not previously been reported, but also that the predictive power of motor symptoms vary depending on the finance task.

The implications of better understanding what predicts difficulties in managing finances may go further than care management, and reach a social perspective. There is a clear overlap between deteriorations in financial capacity and financial exploitation (Lichtenberg, 2016), of which older adults are particularly subjected to. Indeed, the risk of being financially exploited as an older adult increases by 69 percent when having difficulties with one or more IADL as opposed to having no difficulties (Peterson et al., 2014). These everyday functioning deficits can be linked with cognitive changes, and in conjunction with reductions in social capacity account for increases in financial exploitation risk (Spreng et al., 2016). Consequently, the present findings may direct care management of finance management skills towards specific cognitive changes and motor disturbances, in order to not only maintain 
financial skills for longer and maintain independence, but also to potentially help protect people with dementia from the risk of being financially exploited.

Whilst this study has investigated two types of finance management (bills and taxes) and benefits from comparing the predictors of both domains, there are some domains which have not been evaluated, including basic monetary skills and bank statement management for example. These domains are outlined in the Financial Capacity Instrument, comprising a total of nine finance domains (Griffith et al., 2003; Marson et al., 2000). Considering this clear distinction of finance skills into domains, it may be important to investigate the predictors of each domain separately in future research. Whilst each of these domains will be intercorrelated, because they are all finance management skills, basic monetary skills may rely on different cognitive, motor, or other factors compared to bill management.

\section{Conclusions}

This study adds novel insights into some of the predictors of individual finance management subtasks (managing bills and taxes). Findings suggest that a large proportion of finance management abilities remain unexplained by cognition and motor functioning, suggesting future research should focus on other potential contributors such as depression, apathy, and environmental factors. Considering the close link between finance management problems and financial exploitation, and the vulnerability of people with dementia to the latter, improved knowledge of the contributors of managing bills and taxes may help in safeguarding vulnerable older adults from financial harm. 


\section{Acknowledgements}

The NACC database is funded by NIA/NIH Grant U01 AG016976. NACC data are contributed by the NIAfunded ADCs: P30 AG019610 (PI Eric Reiman, MD), P30 AG013846 (PI Neil Kowall, MD), P50 AG008702 (PI Scott Small, MD), P50 AG025688 (PI Allan Levey, MD, PhD), P50 AG047266 (PI Todd Golde, MD, PhD), P30 AG010133 (PI Andrew Saykin, PsyD), P50 AG005146 (PI Marilyn Albert, PhD), P50 AG005134 (PI Bradley Hyman, MD, PhD), P50 AG016574 (PI Ronald Petersen, MD, PhD), P50 AG005138 (PI Mary Sano, PhD), P30 AG008051 (PI Thomas Wisniewski, MD), P30 AG013854 (PI M. Marsel Mesulam, MD), P30 AG008017 (PI Jeffrey Kaye, MD), P30 AG010161 (PI David Bennett, MD), P50 AG047366 (PI Victor Henderson, MD, MS), P30 AG010129 (PI Charles DeCarli, MD), P50 AG016573 (PI Frank LaFerla, PhD), P50 AG005131 (PI James Brewer, MD, PhD), P50 AG023501 (PI Bruce Miller, MD), P30 AG035982 (PI Russell Swerdlow, MD), P30 AG028383 (PI Linda Van Eldik, PhD), P30 AG053760 (PI Henry Paulson, MD, PhD), P30 AG010124 (PI John Trojanowski, MD, PhD), P50 AG005133 (PI Oscar Lopez, MD), P50 AG005142 (PI Helena Chui, MD), P30 AG012300 (PI Roger Rosenberg, MD), P30 AG049638 (PI Suzanne Craft, PhD), P50 AG005136 (PI Thomas Grabowski, MD), P50 AG033514 (PI Sanjay Asthana, MD, FRCP), P50 AG005681 (PI John Morris, MD), P50 AG047270 (PI Stephen Strittmatter, MD, PhD). 


\section{References}

Armstrong MJ, Litvan I, et al. Criteria for the diagnosis of corticobasal degeneration. Neurology 2013;80;496.

Beerens HC, de Boer B, Zwakhalen SMG, et al. The association between aspects of daily life and quality of life of people with dementia living in long-term care facilities: a momentary assessment study. Int Psychogeriatrics 2016; 28(8):1323-1331.

Bensimon G, Ludolph A, Agid Y, Vidailhet M, Payan C, Leigh PN, NNIPPS Study Group. Riluzole treatment, survival and diagnostic criteria in Parkinson plus disorders: the NNIPPS study. Brain 2009;132(Pt 1):156-171.

Berezuk C, Ramirez J, Black SE, et al. Managing money matters: Managing finances is associated with functional independence in MCl. Int J Geriatr Psychiatr 2017; doi: 10.1002/gps.4817.

Cahn DA, Sulivana EV, Shear PK, et al. Component Processes to Physical and Instrumental Activities of Daily Living in Parkinson's Disease. Arch Clin Neuropsy 1998;13(7):575-583.

Cotrell V, Wild K, Bader T. Medication management and adherence among cognitively impaired older adults. J Gerontol Soc Work. 2006; 47(3-4):31-46.

De Paula JJ, Albuquerque MR, Lage GM, et al. Impairment of fine motor dexterity in mild cognitive impairment and Alzheimer's disease dementia: association with activities of daily living. Revista Brasileira de Psiqiatria 2016;38(3): doi: 10.1590/1516-4446-2015-1874

Devanand DP, Xinhua L, Brown PJ. Impact of functional deficits in instrumental activities of daily living in mild cognitive impairment: a clinical algorithm to predict progression to dementia. Alz Dis Assoc Disord 2017;31(1):55-61.

Ferman TJ, Smith GE, Boeve BF, et al. Neuropsychological differentiation of dementia with Lewy bodies from normal aging and Alzheimer's disease. Clin Neuropsychol 2006; 20(4):623-636.

Folstein MF, Folstein SE, McHugh PR. Mini Mental State- A practical method for grading the cognitive state of patients for the clinician. J Psychiatr Res 1975;12:189-198.

Giebel CM, Sutcliffe C, Challis D. Hierarchical decline of the initiative and performance of complex activities of daily living in dementia. J Geriatr Psychiatr Neurol 2017;30(2):96-103.

Kaplan EF, Goodglass H, Weintraub S. The Boston Naming Test. Philadelphia: Lea \& Febiger, 1983.

Kaufer DI, Cummings JL, Ketchel P, et al. Validation of the NPI-Q, a Brief Clinical Form of the Neuropsychiatric Inventory. J Neuropsychiatr Clin Neurosci 2000;12(2):233-239.

Knapskog AB, Barca ML, Engedal K. Prevalence of depression among memory clinic patients as measured by the Cornell Scale of Depression in Dementia. Aging Ment Health 2014;18:579-587.

Lichtenberg PA. The Intersection of Financial Exploitation and Financial Capacity. Am Psychol 2016;71(4):312-320.

Manthorpe J, Samsi K, Rapaport J. Responding to the financial abuse of people with dementia: a qualitative study of safeguarding experiences in England. Int Psychogeriatr 2012;24(9):1454-1464.

Marson DC. Loss of Financial Competency in Dementia: Conceptual and Empirical Approaches. Aging Neuropsychol Cognition 2001;8(3):164-181.

Marson DC, Sawrie SM, Snyder S, et al. Assessing financial capacity in patients with Alzheimer's Disease: A conceputal model and prototype instrument. Arch Neurol 2000;57:877-884.

Martyr, A., Nelis, S.M., \& Clare, L. (2014). Predictors of perceived functional ability in early-stage dementia: self-ratings, informant ratings and discrepancy. International Journal of Geriatric Psychiatry, 29, 852-862. 
McKeith IG, Rowan E, Askew K, et al. More severe functional impairment in dementia with lewy bodies than Alzheimer disease is related to extrapyramidal motor dysfunction. AM J Geriatr Psychiatry 2006;14(7):582-588.

McKhann GM, Knopman DS, Chertkow $\mathrm{H}$, et al. The diagnosis of dementia due to Alzheimer's disease: recommendations from the National Institute on Aging - Alzheimer's Association workgroups on diagnostic guidelines for Alzheimer's disease. Alzheimers Dementia 2011;7(3):263-269.

Moheb N, Mendez MF, Kremen SA, Teng E. Executive Dysfunction and Behavioral Symptoms are associated with deficits in instrumental activities of daily living in frontotemporal dementia. Dementia Geriatr Cog Disord 2017;43:89-99.

Morris, J. C. (1993). The Clinical Dementia Rating (CDR): Current version and scoring rules. Neurology, 43(11), 2412-2414.

Peisah $\mathrm{C}$, Bhatia $\mathrm{S}$, Macnab J, Brodaty $\mathrm{H}$. Knowledge translation regarding financial abuse and dementia for the banking sector: the development and testing of an education tool. Int $\mathrm{J}$ Geriatr Psychiatr 2016;31(7):702-707.

Peres $\mathrm{K}$, Helmer $\mathrm{C}$, Amieva $\mathrm{H}$, et al. Natural history of decline in instrumental activities of daily living performance over the 10 years preceding the clinical diagnosis of dementia: a prospective populationbased study. J Am Geriatrc Soc 2008;56(1):37-44.

Peterson JC, Burnes DPR, Caccamise PL, et al. Financial Exploitation of Older Adults: A PopulationBased Prevalence Study. J Gen Int Med 2014;29(12):1615-1623.

Pfeffer RI, Kurosaki TT, Harrah CH, et al. Measurement of Functional Activity in Older Adults in the Community. J Gerontol 1982; 37(3):323-329.

Raskovsky K, Hodges JR, Knopman D, et al. Sensitivity of revised diagnostic criteria for the behavioural variant of frontotemporal dementia. Brain 2011;134(Pt 9):2456-2477.

Razani J, Casas R, Wong JT, Lu P, Alessi C, Josephson K. Relationship between executive functioning and activities of daily living in patients with relatively mild dementia. Applied Neuropsychol 2007;14(3):208-214.

Shao Z, Janse E, Visser K, Meyer AS. What do verbal fluency tasks measure? Predictors of verbal fluency performance in older adults. Front Psychol 2014;5:772.

Sherod MG, Griffith HR, Copeland J, et al. Neurocognitive predictors of financial capacity across the dementia spectrum: Normal aging, mild cognitive impairment, and Alzheimer's disease. J Int Neuropschol Soc 2009;15(2):258-267.

Smith D, Lovell J, Weller C, et al. A systematic review of medication non-adherence in persons with dementia or cognitive impairment. PLOS One 2017; doi: 10.1371/journal.pone.0170651

Spreng RN, Karlawish J, Marson DC. Cognitive, social, and neural determinants of diminished decisionmaking and financial exploitation risk in aging and dementia: A review and new model. J Elder Abuse Neglect 2016;28:320-344.

Sudo FK, Laks J. Financial capacity in dementia: a systematic review. Aging Ment Health 2017;21(7):677-683.

Wechsler D, Coalson DL, Raiford SE. WAIS-III: Wechsler Adult Intelligence Scale. San Antonio, TX: Psychological Corporation, 1997.

Woodbridge R, Sullivan MP, Harding E, et al. Use of the physical environment to support everyday activities for people with dementia: A systematic review. Dementia 2016; doi: $10.1177 / 1471301216648670$

Yoshii I, Satake Y, Kitaoka K, et al. Relationship between dementia degree and gait ability after surgery of proximal femoral fracture: Review from Clinical Pathway with Regional Alliance data of rural region in Japan. Journal Orthopaedic Scie 2016;21(4):481-486.

Zawacki TM, Grace J, Paul R, et al. Behavioral Problems as Predictors of Functional Abilities of Vascular Dementia Patients. J Neuropsychiatr Clin Neurosci 2002;14(3):296-302. 


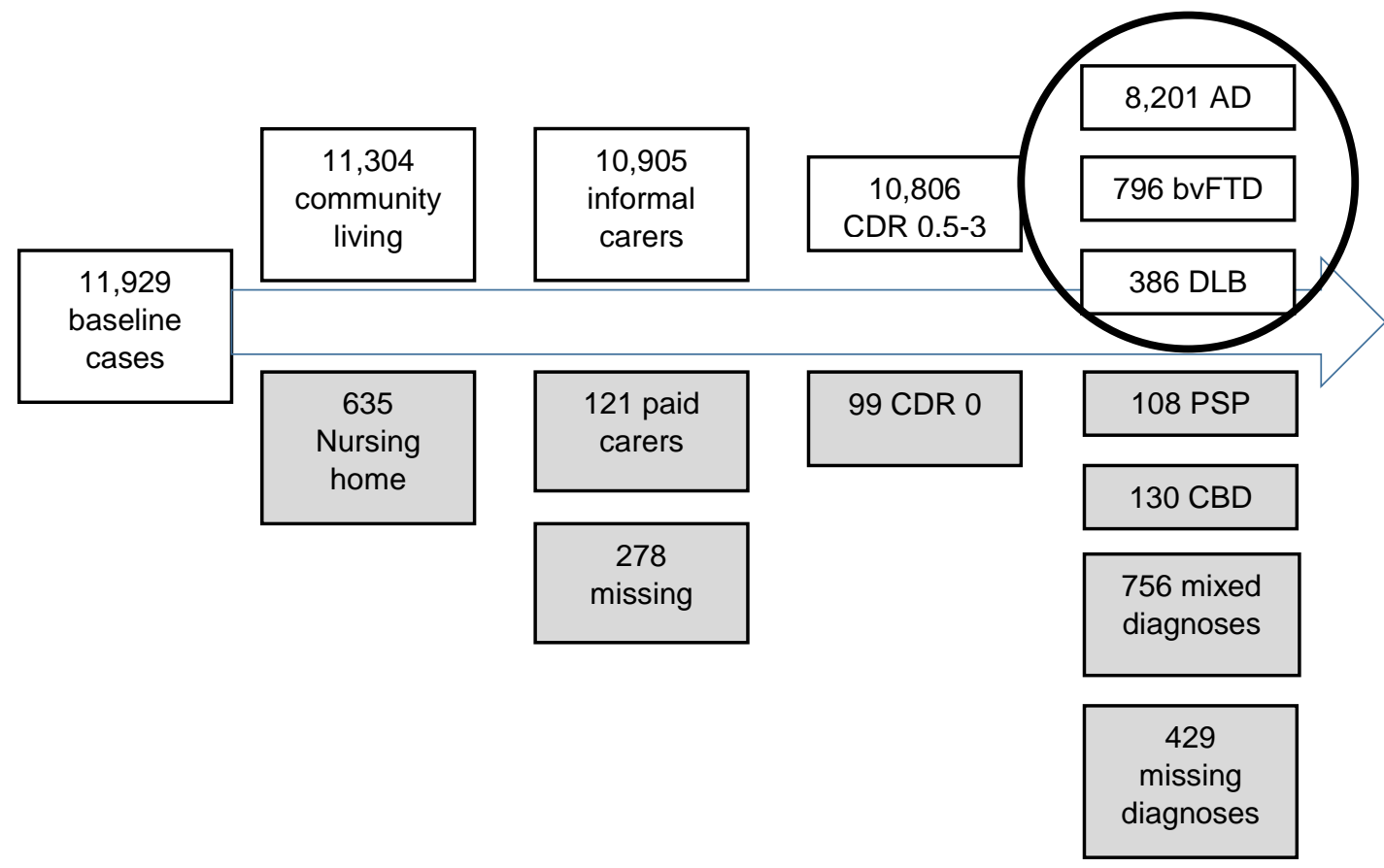

Figure 1. Flowchart of case selection for analysis

White boxes indicate the flow of the included patient cases. Grey shaded boxes indicate the flow of the excluded patient cases. The final number of included patient cases was 9,383 and is circled in the diagram. 
Table 1. Demographic characteristics across dementia subtypes

\begin{tabular}{|c|c|c|c|c|}
\hline & $\begin{array}{l}\text { AD } \\
(n=8,201)\end{array}$ & $\begin{array}{l}\text { bvFTD } \\
(n=796)\end{array}$ & $\begin{array}{l}\text { DLB } \\
(n=386)\end{array}$ & ANOVA/ Chi² \\
\hline \multicolumn{5}{|l|}{ People with dementia } \\
\hline Age, Mean (SD) & $74.5(9.9)^{a, b}$ & $62.9(9.4)^{b}$ & $72.9(8.0)$ & $\begin{array}{l}F(2,9380)=48,790.69 \\
p<.001\end{array}$ \\
\hline Education, Mean (SD) & $14.0(3.8)^{a, b}$ & $15.1(3.2)$ & $14.7(3.7)$ & $F(2,9296)=36.71, p<.001$ \\
\hline Gender & & & & $X^{2}=232.43, p<.001$ \\
\hline Female & $4,636(56.5)$ & 304 (38.2) & $96(24.9)$ & \\
\hline Male & $3,565(43.5)$ & $492(61.8)$ & $290(75.1)$ & \\
\hline Ethnicity & & & & $X^{2}=138.05, p<.001$ \\
\hline White & $6,617(81.0)$ & 742 (94.2) & $343(89.1)$ & \\
\hline $\begin{array}{c}\text { Black/African } \\
\text { American }\end{array}$ & $1,069(13.1)$ & $17(2.2)$ & $25(6.5)$ & \\
\hline Other & $482(5.9)$ & $29(3.6)$ & $17(4.4)$ & \\
\hline Marital status & & & & $X^{2}=187.87, p<.001$ \\
\hline Married & $5,416(66.3)$ & $643(80.9)$ & 319 (82.9) & \\
\hline Widowed & $1,780(21.8)$ & $37(4.7)$ & $40(10.4)$ & \\
\hline Divorced/Separated & $680(8.3)$ & $82(10.3)$ & $17(4.5)$ & \\
\hline Other & $288(3.5)$ & $41(4.1)$ & $9(2.4)$ & \\
\hline CDR Global & & & & $X^{2}=44.36, p<.001$ \\
\hline 0.5 & $2,591(31.6)$ & $198(24.9)$ & $119(30.8)$ & \\
\hline 1 & $3,835(46.8)$ & $355(44.6)$ & $176(45.6)$ & \\
\hline 2 & $1,297(15.8)$ & $160(20.1)$ & $65(16.8)$ & \\
\hline 3 & $478(5.8)$ & $83(10.4)$ & $26(6.7)$ & \\
\hline \multicolumn{5}{|l|}{ FAQ Total } \\
\hline Bills & & & & $X^{2}=34.94, p<.001$ \\
\hline Independent & 762 (10.7) & $65(8.9)$ & $18(5.5)$ & \\
\hline Difficulty & $986(13.8)$ & $75(10.3)$ & $28(8.6)$ & \\
\hline Requires assistance & $1,519(21.2)$ & $137(18.8)$ & $70(21.4)$ & \\
\hline Dependent & $3,885(54.3)$ & 450 (61.9) & $211(64.5)$ & \\
\hline Taxes & & & & $X^{2}=29.5, p<.001$ \\
\hline Independent & $586(8.7)$ & $44(6.2)$ & $15(4.7)$ & \\
\hline Difficulty & $640(9.5)$ & $52(7.4)$ & $15(4.7)$ & \\
\hline Requires assistance & $1,316(19.6)$ & $124(17.6)$ & $65(20.2)$ & \\
\hline Dependent & $4,176(62.2)$ & $485(68.8)$ & $227(70.5)$ & \\
\hline \multicolumn{5}{|l|}{ Carers } \\
\hline Gender & & & & $\mathrm{X}^{2}=55.1, \mathrm{p}<.001$ \\
\hline Female & $5,437(66.3)$ & $563(70.7)$ & $323(83.7)$ & \\
\hline Male & $2,764(33.7)$ & $233(29.3)$ & $63(16.3)$ & \\
\hline Ethnicity & & & & $X^{2}=115.69, p<.001$ \\
\hline White & $6,595(80.9)$ & 739 (93.2) & $343(89.6)$ & \\
\hline $\begin{array}{l}\text { Black/African } \\
\text { American }\end{array}$ & $1,045(12.8)$ & $19(2.4)$ & $23(6.0)$ & \\
\hline Other & $508(6.3)$ & $35(4.4)$ & $17(4.4)$ & \\
\hline Relationship & & & & $X^{2}=206.6, p<.001$ \\
\hline Spouse & $4,862(59.3)$ & $614(77.1)$ & 308 (79.8) & \\
\hline Child & 2,653 (32.3) & $104(13.1)$ & $71(18.4)$ & \\
\hline Other & $686(8.4)$ & $78(9.8)$ & $7(1.8)$ & \\
\hline
\end{tabular}

NOTE: All data shown in $\mathrm{N}(\%)$, unless otherwise stated. 
$A D=A l z h e i m e r$ 's Disease; bvFTD=behavioural variant Fronto-Temporal Dementia; $C D R=$ Clinical Dementia Rating Scale; DLB=Dementia with Lewy Bodies; FAQ=Functional Assessment Questionnaire 
Table 2. Performance on neuropsychological measures across dementia subtypes

\begin{tabular}{|c|c|c|c|c|}
\hline & $\begin{array}{l}A D \\
(n=8,201)\end{array}$ & $\begin{array}{l}\text { bvFTD } \\
(n=796)\end{array}$ & $\begin{array}{l}\text { DLB } \\
(n=386)\end{array}$ & ANOVA \\
\hline MMSE & $19.9(6.3)^{a, b}$ & $21.2(7.4)$ & $21.3(6.2)$ & $\begin{array}{l}\mathrm{F}(2,8465)=20.42 \\
\mathrm{p}<.001\end{array}$ \\
\hline $\begin{array}{l}\text { Digit Span } \\
\text { forward }\end{array}$ & $6.6(2.6)$ & $6.7(2.3)$ & $6.6(2.2)$ & $\begin{array}{l}F(2,7757)=.311, \\
p=.733\end{array}$ \\
\hline $\begin{array}{l}\text { Digit Span } \\
\text { backward }\end{array}$ & $4.2(2.5)^{b}$ & $4.2(2.1)$ & $3.9(1.8)$ & $\begin{array}{l}\mathrm{F}(2,7690)=3.296 \\
\mathrm{p}<.005\end{array}$ \\
\hline Trail A & $74.1(42.4)^{a, b}$ & $63.7(39.2)^{\mathrm{b}}$ & $97.9(42.9)$ & $\begin{array}{l}\mathrm{F}(2,7488)=63.39 \\
\mathrm{p}<.001\end{array}$ \\
\hline Trail B & $214.9(87.6)^{a, b}$ & $175.2(93.8)^{b}$ & $255.8(71.3)$ & $\begin{array}{l}\mathrm{F}(2,5532)=64.15 \\
\mathrm{p}<.001\end{array}$ \\
\hline WAIS & $24.2(13.8)^{a, b}$ & $30.4(14.8)^{\mathrm{b}}$ & $18.2(11.1)$ & $\begin{array}{l}\mathrm{F}(2,6576)=70.88 \\
\mathrm{p}<.001\end{array}$ \\
\hline Boston & $18.8(7.6)^{\mathrm{a}, \mathrm{b}}$ & $20.2(8.5)^{b}$ & $22.5(6.0)$ & $\begin{array}{l}\mathrm{F}(2,7596)=42.39 \\
\mathrm{p}<.001\end{array}$ \\
\hline Animals & $10.2(5.2)$ & $9.9(6.2)$ & $10.4(5.1)$ & $\begin{array}{l}F(2,8242)=1.24, \\
p=.291\end{array}$ \\
\hline Vegetables & $6.7(3.9)^{a}$ & $6.2(4.2)$ & $6.6(3.5)$ & $\begin{array}{l}F(2,8077)=3.97, \\
p<.05\end{array}$ \\
\hline
\end{tabular}



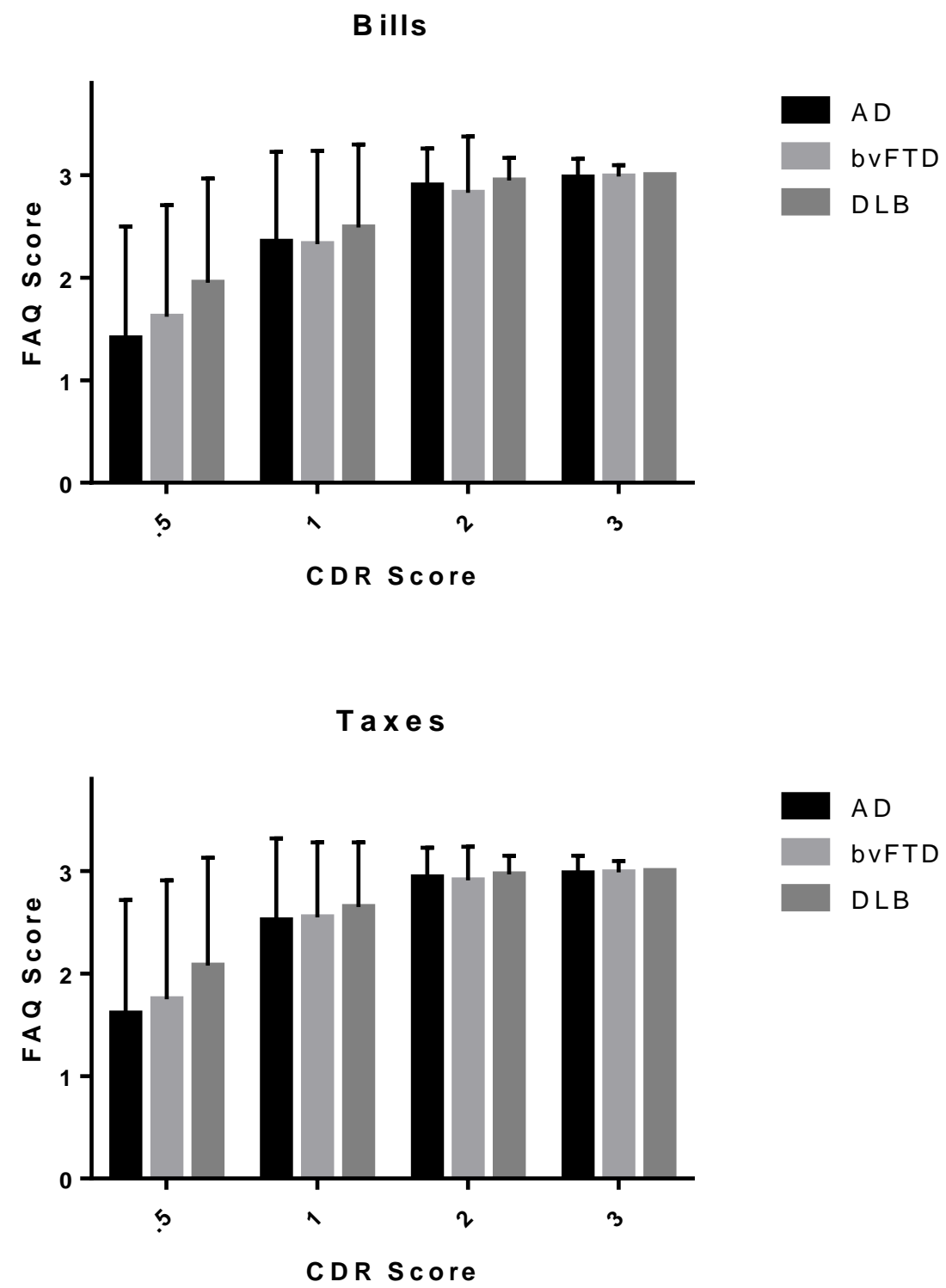

Figure 2. Average performance on paying bills and managing taxes by dementia severity and subtype 
Table 3. Contributors to finance management across the dementia sample

\section{Bills}

\begin{tabular}{lllll}
\hline Model 1 & Standardised B & $\mathbf{t}$ & $\mathbf{p}$-value & $\mathbf{9 5 \% ~ C l}$ \\
\hline Age & .040 & 2.890 & .004 & $.001-.007$ \\
\hline Gender & .030 & 2.239 & .025 & $.008-.121$ \\
\hline Dementia type & & & & \\
$\quad$ AD diagnosis & .015 & .630 & .528 & $-.106-.207$ \\
$\quad$ bvFTD diagnosis & .087 & 3.746 & $<.001$ & $.164-.523$ \\
\hline Executive & -.255 & -16.219 & $<.001$ & $-.022--.017$ \\
functioning (WAIS) & & & & \\
\hline Language (Boston) & .033 & 2.094 & .036 & $.000-.009$ \\
\hline Digit Span backward & -.026 & -1.763 & .078 & $-.029-.002$ \\
\hline Verbal fluency & -.140 & -9.053 & $<.001$ & $-.047--.030$ \\
(Vegetables) & & & & \\
\hline Motor functioning & & & & $.002-.199$ \\
\hline Falls & .026 & 2.009 & .045 & $.182-.329$ \\
\hline Slowness & .094 & 6.794 & $<.001$ & \\
\hline$R^{2}$ & .138 & & & \\
\hline
\end{tabular}

\begin{tabular}{lllll}
\hline Taxes & & & & \\
\hline Model 2 & Standardised B & $\mathbf{t}$ & $\mathbf{p}$-value & $\mathbf{9 5 \% ~ C l}$ \\
\hline Age & .057 & 3.882 & $<.001$ & $.003-.009$ \\
\hline Gender & .083 & 5.901 & $<.001$ & $.112-.224$ \\
\hline $\begin{array}{l}\text { Dementia type } \\
\quad \text { AD diagnosis }\end{array}$ & -.017 & & & \\
$\quad$ bvFTD diagnosis & .068 & -.695 & .487 & $-.206-.098$ \\
\hline Executive & -.223 & 2.798 & .005 & $.075-.424$ \\
functioning (WAIS) & & -13.528 & $<.001$ & $-.018--.014$ \\
\hline Language (Boston) & .038 & & & $.001-.010$ \\
\hline Digit Span backward & -.026 & 2.335 & .020 & $-0.28-.002$ \\
\hline Verbal fluency & -.127 & -1.723 & .085 & $-.041--.025$ \\
(Vegetables) & & -7.866 & $<.001$ & \\
\hline Motor functioning & & & & $.001-.196$ \\
\hline Falls & .028 & & & $.126-.271$ \\
\hline Slowness & .078 & 1.990 & .047 & \\
\hline$R^{2}$ & .114 & 5.376 & $<.001$ & \\
\hline
\end{tabular}

Model fit for paying bills: $\mathrm{F}$ change $(10,5538)=88.553, p<.001$;

Model fit for taxes: F change $(10,5188)=66.661, p<.001$ 